\title{
Long-Term Safety and Quality of Life after Vibroplasty in Sensorineural Hearing Loss: Short/Long Incus Process Coupler
}

\author{
Stefan Herwig Edlinger ${ }^{a}, b \quad$ Martin Hasenzagl $^{a} \quad$ Philipp Schoerg ${ }^{a, b}$ \\ Stefanie Muck ${ }^{a}$ Astrid Magele ${ }^{a, b}$ Georg Mathias Sprinzla, b \\ aDepartment of Otorhinolaryngology, University Hospital St. Pölten, St. Poelten, Austria; \\ ${ }^{b}$ Karl Landsteiner University of Health Sciences, Krems, Austria
}

\section{Keywords}

Vibrant soundbridge · Sensorineural hearing loss · Short process coupler · Long process coupler · Quality of life · AQoL8d

\begin{abstract}
Objective: The study shows the long-term effectiveness, safety, and quality of life after Vibrant Soundbridge (VSB) implantation in sensorineural hearing loss (SNHL) using the short process coupler (SP) or the long process coupler (LP). Methods: This retrospective study evaluated 77 VSB cases. Follow-up (F/U) time-dependent objective measurements (audiological outcomes), subjective data collection (qualityof-life questionnaire), and safety measures are presented. Results: Sixty-two ears were included in the analysis with up to 116 months of postsurgical F/U data (mean 32.15 \pm 37.97 months LP and SP coupler). Fifty-three ears (13 bilateral cases) received the LP coupler and 9 subjects the SP coupler. The post-operative bone conduction thresholds remained stable and, in both groups, $<10 \mathrm{~dB}$. The benefit in word recognition scores measured at $65 \mathrm{~dB}$ SPL and $80 \mathrm{~dB}$ SPL showed no significant difference between the couplers $(p=0.559$ and $p=0.088$, respectively). The functional gain was not sig-
\end{abstract}

nificantly different $(p>0.05)$ with a mean of $20.91 \pm 9.77$ and $17.19 \pm 5.75$ for LP and SP coupler, respectively. The utility score deciphered from the Assessment of Quality-of-life Questionnaire-8 dimensions revealed a mean score of $0.75 \pm$ 0.16 which is not significantly different to the age- and sexmatched healthy control group with $0.81 \pm 0.02(p=0.3547)$. Conclusion: The Incus Vibroplasty utilizing both couplers is a safe and effective method to treat mild-to-severe SNHL. Both fixation methods of the floating mass transducer exhibit good clinical and audiological outcomes with high patient quality of life. The SP coupling method can be a good alternative when the long process is anatomically inaccessible, or the approach is limited due to anatomical reasons.

(c) 2021 The Author(s)

Published by S. Karger AG, Basel

\section{Introduction}

The Vibrant Soundbridge ([VSB] MED-EL Company) is an active middle ear implant (AMEI) intended for people with sensorineural, conductive, or mixed hearing loss. It is a modern and effective treatment option for cases who's hearing loss is not profound enough for a cochlear implant, but conventional hearing aids are not tolerated
C 2021 The Author(s)

Published by S. Karger AG, Basel

This is an Open Access article licensed under the Creative Commons Attribution-NonCommercial-4.0 International License (CC BY-NC) (http://www.karger.com/Services/OpenAccessLicense), applicable to the online version of the article only. Usage and distribution for commercial purposes requires written permission.
Correspondence to:

Georg Mathias Sprinzl, georg.sprinzl@ stpoelten.lknoe.at 
or do not provide enough satisfying improvement. MEIs were designed to address the deficiencies and shortcomings of HAs that made it difficult for some patients to be fitted, due to either medical problems such as absent ear canal, intolerance to the ear mold, eczema of the ear canal, collapsing ear canals; or technical problems such as feedback, resonance, autophonia, and poor sound quality [Labassi et al., 2017; Lee et al., 2017]. The system is indicated for both, children and adults, but majority of candidates are older than 55 years [Baumgartner et al., 2010; Cremers et al., 2010; Frenzel et al., 2015]. The efficacy and safety of the VSB for all indications has been demonstrated in the past decade in a number of studies [Fisch et al., 2001; Fraysse et al., 2001; Snik et al., 2001; Sterkers et al., 2003; Schmuziger et al., 2006; Baumgartner et al., 2010; Cremers et al., 2010; Pok et al., 2010; Colletti et al., 2013; Frenzel et al., 2015; Labassi et al., 2017; Geiger et al., 2019; Sprinzl et al., 2020] systematically evaluated in several review articles [Ernst et al., 2016; Bruchhage et al., 2017; Kliess et al., 2018]. The long-term audiological outcome of patients with the VSB coupled to the round window was recently reported by Sprinzl et al., 2020. In this study, the patients with conductive or mixed hearing loss experienced considerable and stable hearing benefit with their VSB device up to 74 months of follow-up (F/U) and the low revision rates were directly related to the underlying pathology of cholesteatoma. Other study groups evaluated long-term outcomes of the VSB recently and reported acceptable complication rates combined with satisfactory audiological benefit for all hearing loss types and coupling modalities for up to 17.9 years $\mathrm{F} / \mathrm{U}$ [Schmuziger et al., 2006; Colletti et al., 2013; Zahnert et al., 2018; Brkic et al., 2019].

In subjects suffering from sensorineural hearing loss (SNHL), the initial attachment of the FMT was to the long process of the incus requiring a wide posterior tympanotomy for proper placement and accurate clip attachment. This delicate procedure in this size-limited area may damage surrounding structures such as chorda tympani nerve, facial nerve, ossicles, promontory, pyramidal eminence, or the tympanic membrane. An alternative coupling method was developed which utilizes the short incus process as a fixation point for the FMT, aiming to reduce surgical risks as well as surgery time. Recent research reported no significant differences in the post-operative audiological measurements between the 2 coupling modalities [Schraven et al., 2014; Mlynski et al., 2015]. In these studies, a measurement of the vibration responses of the stapes footplate and the round window membrane were made and outcomes were not signifi- cantly different between long process (LP) and short process (SP) coupling. Literature on revision and explantation rates due to technical or medical reasons for longterm data comparing those coupling methods are still scarce. Medical-, audiological and complication outcomes including the mean time of use in dependence of the coupling approach used were assessed. Post-operative audiological benefit characterized as the functional gain (FG) as well as improvement in Word Recognition Scores via the Freiburger monosyllables test was evaluated. Additionally, safety of the implant regarding the inner ear function was measured as a function of pre- versus postoperative bone conduction (BC) change. Kaplan-Meier survival analysis was performed calculating for each time interval and respective coupler a "survival" probability calculated as the number of subjects surviving divided by the number of patients at risk. Therefore, this retrospective chart review aimed to investigate the long-term stability and efficacy of the 2 coupling modalities in patients with mild-to-severe SNHL implanted with an AMEI.

\section{Materials and Methods}

A retrospective cohort study was carried out at the ENT department of the University Hospital St. Poelten, Austria. In total, data from 77 patients suffering from SNHL were included in this study between 2008 and 2019. All patients did not benefit from hearing aids or prior reconstruction surgeries. Fifteen subjects were lost to $\mathrm{F} / \mathrm{U}$ as they were implanted at another clinic and the ongoing $\mathrm{F} / \mathrm{U}$ occurred there. Forty-nine cases (62 ears) were included in the final evaluation. The study was approved by the ethical review committee Sigmund Freud Private University, Department of Medicine (EK089/2019). Five of the presented subjects were part of a bilateral study published by Seebacher et al. with the ethical review committee for Lower Austria (GS4-EK-4/467-2017) (all part of the LP-group) [Seebacher et al., 2020].

Clinical routine involves audiological tests, performed in a sound isolated room with audiometers operated by certified speech therapists. Pure-tone audiograms with BC thresholds at $0.25,0.5$, $1,2,3$, and $4 \mathrm{kHz}$, and air conduction thresholds measured at 0.25 , $0.5,1,2,4,6$, and $8 \mathrm{kHz}$ were performed. Outcomes are presented as pure-tone thresholds over the frequencies $0.5,1,2$, and $4 \mathrm{kHz}$ (PTA4).

Freiburger monosyllabic speech tests are performed at 65 and $80 \mathrm{~dB}$ to analyse the percentage of word understanding in the preand post-operative condition, and the benefit was calculated. The Assessment of Quality-of-life Questionnaire-8 dimensions (AQoL-8d) is a multi-attribute health utility instrument used to assess the general health status. Subjects who came for routine clinical examinations in the past 12 months received the AQoL-8d to evaluate their individual generic quality-of-life status and self-perceived benefit from the intervention. Results were compared to their age- and sex-matched healthy controls as published by as the routine distribution of AQoL8d preoperative as well as post-operative started not before 2020 [Hawthorne and Osborne, 2005]. 
Table 1. Patient demographics

\begin{tabular}{|c|c|c|c|c|c|c|c|}
\hline \# Subjects & Gender & $\begin{array}{l}\text { Age at } \\
\text { implantation }\end{array}$ & $\begin{array}{l}\text { Implant } \\
\text { side }\end{array}$ & $\begin{array}{l}\text { Surgery } \\
\text { time, } \\
\text { min }\end{array}$ & Complication & $\begin{array}{l}\text { Time till } \\
\text { revision, } \\
\text { months }\end{array}$ & $\begin{array}{l}\text { Total F/U, } \\
\text { months }\end{array}$ \\
\hline Mean & & 63.10 & $29 \mathrm{R}$ & 73.19 & \multirow{3}{*}{$\begin{array}{l}\text { No complications in } \\
n=51\end{array}$} & $\mathrm{~N} / \mathrm{A}$ & 32.15 \\
\hline $\mathrm{SD}$ & 18 females & 12.93 & $21 \mathrm{~L}$ & 29.80 & & $\mathrm{~N} / \mathrm{A}$ & 37.97 \\
\hline $\operatorname{Max}$ & & 90.00 & & 140.00 & & $\mathrm{~N} / \mathrm{A}$ & 116.00 \\
\hline LP39 & Female & 75.00 & $\mathrm{R}$ & 54.00 & FMT re-positioned & 5 & 10.00 \\
\hline LP40 & Male & 54.00 & $\mathrm{~L}$ & 81.00 & $\begin{array}{l}\text { Implant failure due to } \\
\text { cholesteatoma }\end{array}$ & 17 & 17.00 \\
\hline \multicolumn{8}{|c|}{$\begin{array}{l}\text { ALL LP-coupler mean outcomes LP01-LP40 (53 ears) } \\
\text { LP01-LP40 ALL }\end{array}$} \\
\hline \multicolumn{8}{|c|}{$\begin{array}{l}\text { SP coupler mean outcomes SP01-SP08 (8 ears) complication free } \\
\text { SP01-SP08 }\end{array}$} \\
\hline Mean & & 61.25 & $5 \mathrm{R}$ & 71.33 & \multirow{4}{*}{ No complications in $n=8$} & $\mathrm{~N} / \mathrm{A}$ & 12.25 \\
\hline SD & 5 females & 7.05 & $3 \mathrm{~L}$ & 5.99 & & $\mathrm{~N} / \mathrm{A}$ & 9.26 \\
\hline Min & 3 males & 43.00 & & 60.00 & & $\mathrm{~N} / \mathrm{A}$ & 1.00 \\
\hline Max & & 66.00 & & 80.00 & & N/A & 32.00 \\
\hline SP09 & Female & 68.00 & $\mathrm{~L}$ & $\mathrm{~N} / \mathrm{A}$ & Change to SP coupler & 6 & 6.00 \\
\hline \multicolumn{8}{|c|}{$\begin{array}{l}\text { ALL SP coupler mean outcomes SP01-SP09 (9 ears) } \\
\text { SP01-SP09 ALL }\end{array}$} \\
\hline Mean & & 62.00 & $5 \mathrm{R}$ & 71.33 & \multirow{3}{*}{ Total: 1 coupler change } & 6 & 11.56 \\
\hline $\mathrm{SD}$ & 6 females & 6.98 & $4 \mathrm{~L}$ & 5.99 & & $\mathrm{~N} / \mathrm{A}$ & 8.95 \\
\hline Min & 3 males & 43.00 & & 60.00 & & $\mathrm{~N} / \mathrm{A}$ & 1.00 \\
\hline
\end{tabular}

Subjects with a complication presented in detail. R, right; L, left; F/U, follow-up; SD, standard deviation.

Complication and revision rates were compared as KaplanMaier Survival Curves for the LP and SP coupler and separated into overall cumulative survival versus device survival. Former was characterized as all complications considered whereas in contrast, the device survival, was defined as devices "not explanted" and still intact such as in cases of coupling verification.

\section{Surgical Procedure}

All surgeries were performed by 2 surgeons (G.M.S. and A.M.) with the majority of cases performed by the senior author at the University Hospital St. Poelten, Department for Otorhinolaryngology, St. Poelten, Austria. Each case was discussed at an implantboard, evaluating preoperative audiological check-up, CT- and MRI-scans. The final decision on which coupling system to be used was based on patient anatomy and preoperative audiometry. For the implantation, a mastoidectomy was drilled and an implant bed was prepared in the occipitotemporal bone. The implantable part of the VSB-system was secured with the integrated screw system. Depending on the coupling method either a posterior tympanotomy or an extended antrotomy was performed and the coupler was attached to the long or the short incus process. In all cases, the posterior wall of the auditory canal was preserved. The patients remained in the hospital for at least 1 night. BC audiometry was performed on the first post-operative day. The implant system was activated 3-5 weeks post-implantation.

\section{Data Analysis}

The statistical analysis was conducted using GraphPad Prism version 5.00 for Windows (GraphPad Software, San Diego, CA, USA, www.graphpad.com). Mann-Whitney test was used to test for significant differences between the coupling conditions for the audiological measurements. Paired $t$-test was applied for the AQoL-8d measurements and their respective age- and sexmatched control. Descriptive statistics were performed for age, gender, average $\mathrm{F} / \mathrm{U}$ and is summarized in Table 1. Audiological as well as utility scores of the AQoL8d questionnaire are summarized in Table 2. The following applies for both tables: subjects with a complication are presented on the individual level, whereas the remaining cohort is summarized as mean, standard deviation, minimum, and maximum outcomes separated for the LP versus the SP coupling group. Audiological performance was tested as FG as well as comparing the Freiburger monosyllabic speech test ben- 
Table 2. Patient audiological and subjective/questionnaire outcomes

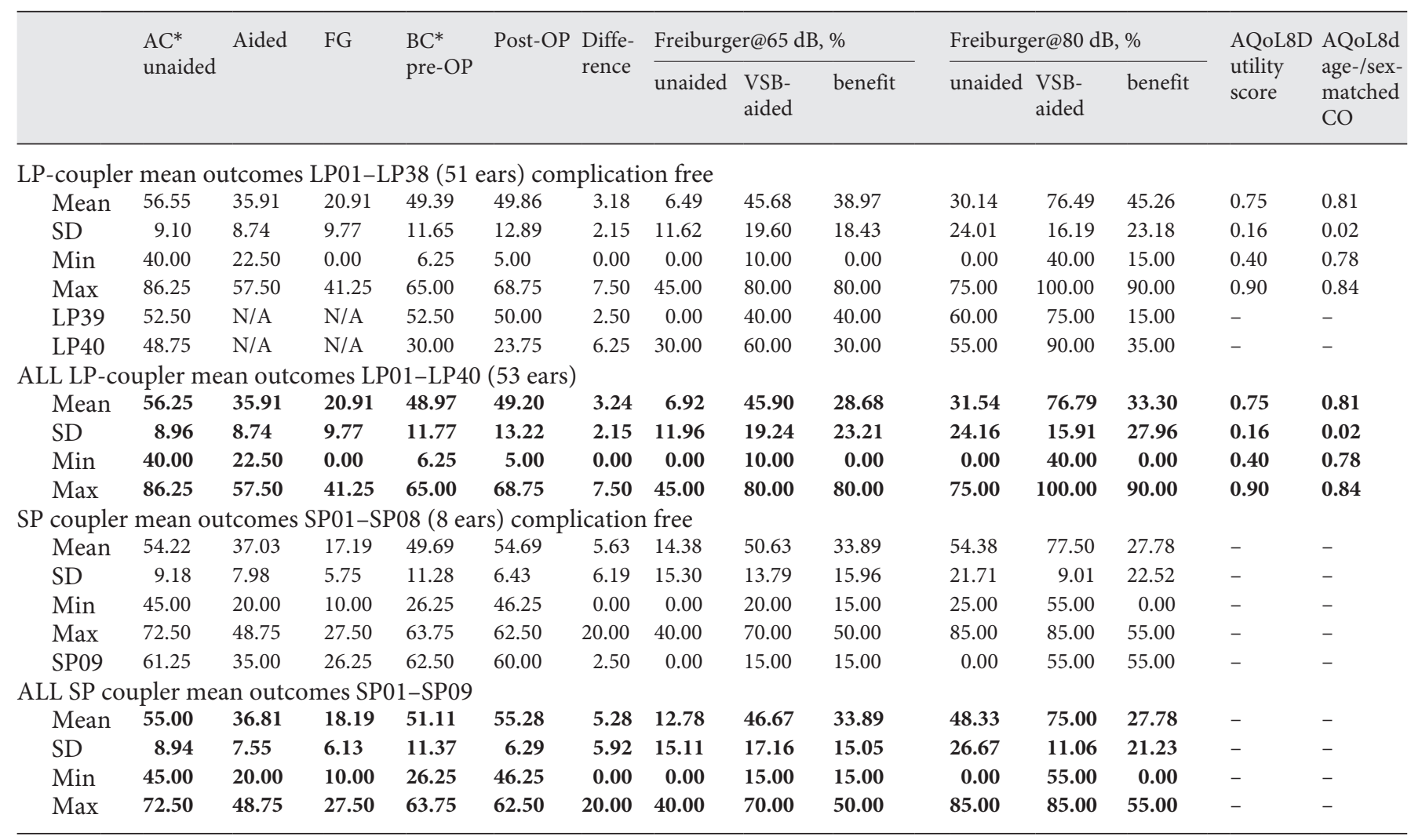

Subjects with a complication presented in detail. AC, air conduction; BC, bone conduction; FG, functional gain; CO, control; VSB, Vibrant Soundbridge; SD, standard deviation; LP, long process. * PTA $_{4}(0.5 ; 1 ; 2 ; 4 \mathrm{kHz})(\mathrm{dB} \mathrm{HL})$ reported.

efit at 65 and $80 \mathrm{~dB}$ (shown in Fig. 1, 2, respectively). Since no preoperative utility scores derived from the AQol8d questionnaire were available, the authors compared the results to the individuals' age- and sex-matched healthy control group [Hawthorne and Osborne, 2005]. Outcomes are depicted in Figure 3. The benefit in word recognition scores was correlated with the AQoL8d obtained utility index in dependence of F/U time for the SP and LP group. In addition, for correlation purposes, the control group was matched with Freiburger normal hearing norms based on the publication by the authors reported a mean age of the tested population of $36.6 \pm 17.1$ years and a mean WRS of $98 \%$ (for both sexes) [Löhler et al., 2013]. Based on our audiological experience with the older population, we assumed a decline in speech understanding of $10 \%$ after the age of 60 , resulting in a mean WRS of $88.2 \%$ for the population $60+$ (Table 2; Fig. 4) [Sprinzl and Riechelmann, 2010; Wolf-Magele et al., 2011]. Correlations between outcome variables of WRS benefit at $65 \mathrm{~dB}$ and AQoL-8d utility scores were assessed by Pearson's correlation coefficient ( $r$ ) and conducted in R Statistical Computing Environment.

Outcomes were rated as statistically significant with a significance level of $p \leq 0.05$. For the safety outcomes, a Kaplan-Meier survival analysis was performed calculating for each coupling modality a "survival" probability calculated as the number of subjects surviving divided by the number of patients at risk. Survival curves were separated into overall cumulative survival versus device survival: former was characterized as all complications considered whereas in contrast, the device survival was defined as devices "not explanted" and still intact such as in cases of coupling verification.

\section{Results}

This retrospective study evaluated 77 VSB cases suffering from SNHL. Surgery was performed by 2 surgeons (G.M.S. and A.M.) between 2008 and 2019. Sixty-two ears were included in the analysis with up to 116 months of postsurgical F/U data (mean $32.15 \pm 37.97$ months). Seventeen subjects had a F/U time below 12 months ( 8 in the LP group and 4 in the SP group) - F/U time-dependent analysis showed no differences, most likely due to too small sample size, and therefore, outcomes were not separated into long- and short-term. Nonetheless, outcomes were investigated taking F/U time into account (Fig. 4). 
Fig. 1. Displayed is the FG for the LP-coupler group (black; filled circle) and the SPcoupler group (grey; filled square). The group respective preoperative values (unfilled symbols) are presented to show that subjects were within the manufacturer's indication limits (light grey box, upper, and lower indication limit in $\mathrm{dB}$ HL). FG, functional gain; LP, long process.

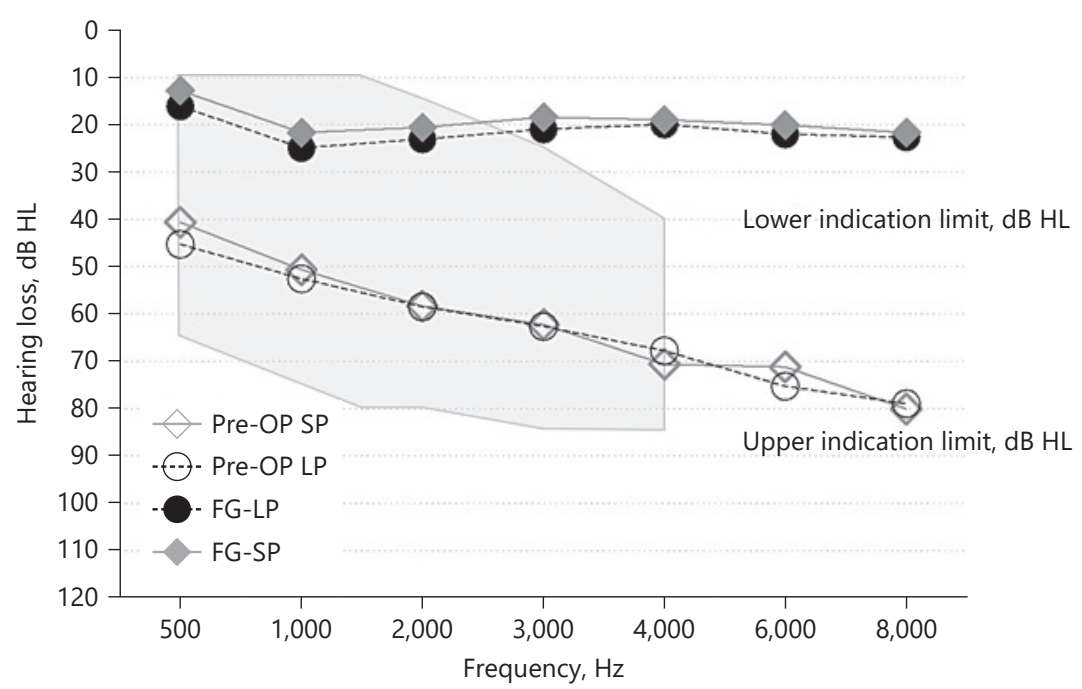

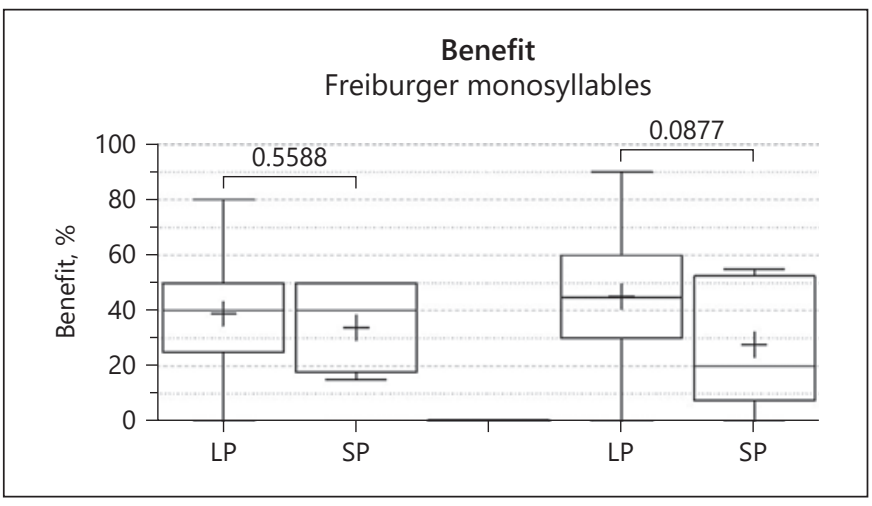

Fig. 2. Box-plot shows the benefit in Word Recognition Score in percent (\%) measured at a presentation level of $65 \mathrm{~dB}$ (left) and at $80 \mathrm{~dB}$ (right). Both measurements were not statistically significant between groups ( $p=0.559$ and $p=0.088$, respectively).

Group distribution was as follows: 53 ears (13 bilateral cases) were performed conventionally with a fixation of the FMT on the incus LP and 9 subjects received alternative coupling on the incus SP. The surgical time between LP and SP coupling was not statistically significant $(p=$ 0.359 ) (Table 1 ). The overall mean age was $62.98 \pm 12.18$ years with the oldest subject (LP coupler) being 90 years at time of surgery (group-specific demographic details are summarized in Table 1).

\section{Objective Benefit}

The benefit in word recognition scores measured at 65 $\mathrm{dB}$ SPL as well as at $80 \mathrm{~dB}$ SPL showed no significant difference between the LP coupler and the SP coupler $(p=$

Long-Term Safety in VSB LP and SP Coupling

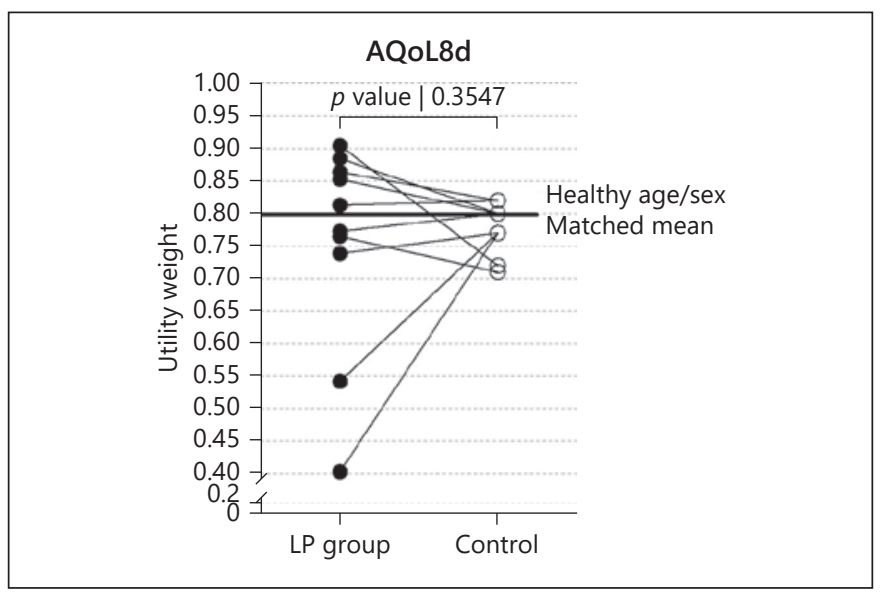

Fig. 3. Assessment of quality-of-life AQOL-8D. Utility scores comparing LP-coupler group scores (left) to the respective healthy ageand sex-matched reference group (right) [Hawthorne and Osborne, 2005] results. Outcomes are not statistically significant ( $p=$ 0.355). The black bar represents the corresponding mean of the healthy control group showing that half the population subjective perception is above that of the healthy population. LP, long process.

0.559 and $p=0.088$, respectively) (Table 2 ). The calculation of the FG revealed no significant difference between the 2 couplers $(p>0.05)$ with a mean FG of $20.91 \pm 9.77$ and $17.19 \pm 5.75$ for LP and SP coupler, respectively (Fig. $1)$.

\section{Subjective Benefit}

The utility score evaluating the quality of life via the AQoL8d revealed a mean score of $0.75 \pm 0.16$ which is not 


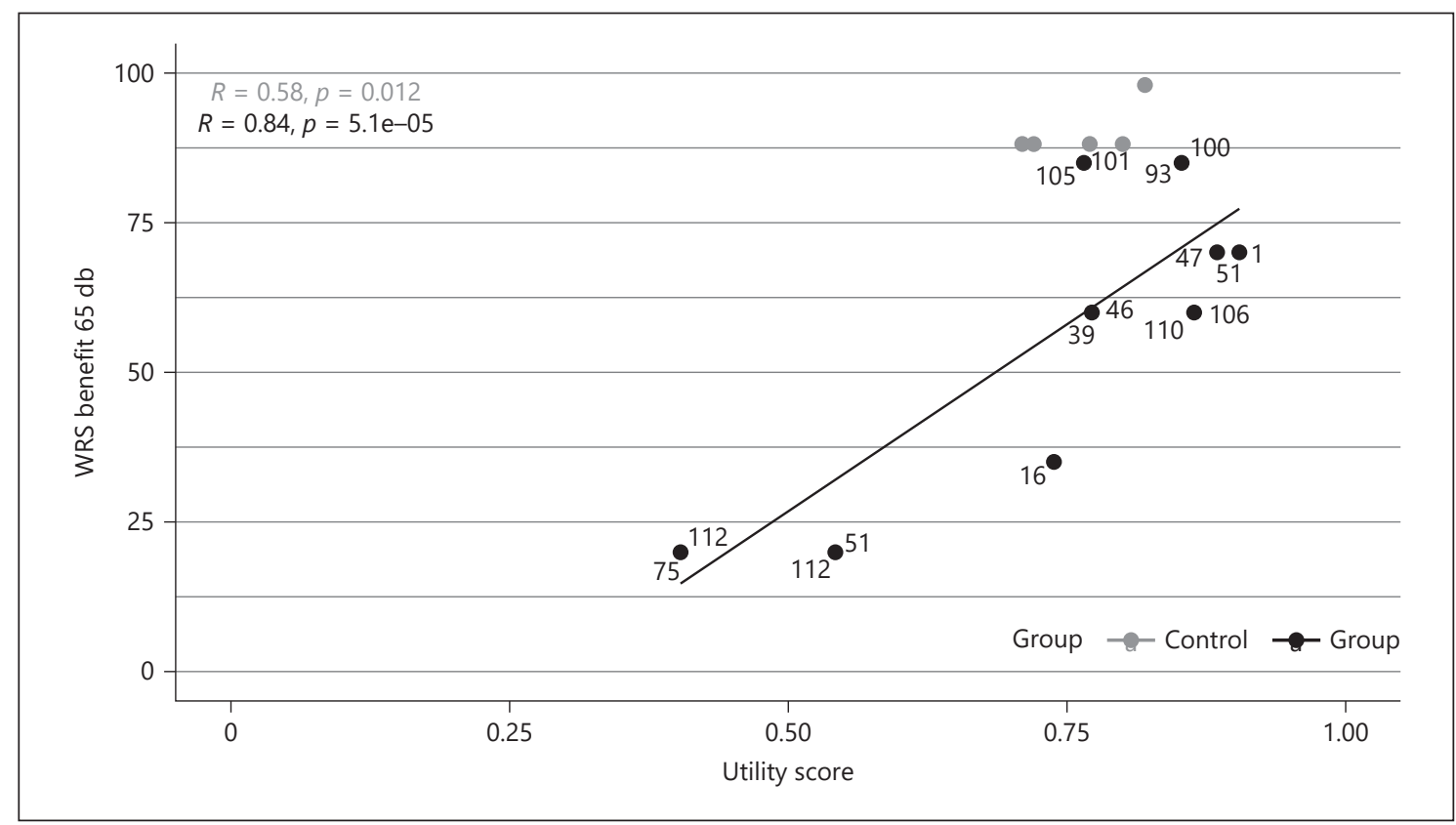

Fig. 4. The Pearson's correlation between the word recognition scores benefit (Freiburger monosyllabic word test at a presentation level of $65 \mathrm{~dB}$ ) versus the overall generic health utility scores produced by the AQoL-8D instrument is shown for the LP group (black) and the normal age- and sex-matched control group (grey). LP, long process.

significantly different to the age- and sex-matched healthy control group with $0.81 \pm 0.02(p=0.3547)$ (Fig. 3,4$)$. The correlation between the subjective benefit (AQoL-8d; general quality of life) and the WRS benefit measured at $65 \mathrm{~dB}$ is shown in Figure 4. The outcome measures correlated well with an $R=0.84 ; p=5.1 \mathrm{e}-05$. The correlation of the extrapolated values for the age- and sex-matched control group for WRS at $65 \mathrm{~dB}$ and Utility AQoL-8d outcomes revealed $R=0.58 ; p=0.012$. Therefore, it can be assumed that subjective outcome, hence, the patients' general health status at the time of questionnaire had a significant effect on the objective measurement of WRS - the better the speech understanding the higher/ better the quality-of-life measure.

\section{Safety}

The post-operative $\mathrm{BC}$ thresholds remained stable in all groups during the investigation period with a mean difference in the LP group of $3.24 \pm 2.15 \mathrm{~dB}$ HL and 5.28 $\pm 5.92 \mathrm{~dB}$ HL in the SP group indicating no inner ear problems. The Kaplan-Meier Survival analysis calculating the "survival" probability for the SP coupler over a course of 32 months and the LP coupler over a course of 54 months is shown in Figure 5. Two complications out of 53 ears occurred in the LP group, where 1 subject re- quired repositioning of the FMT, and the second subject had a device failure due to re-occurring cholesteatoma. The survival proportion of the device survival in the LP group lies at $90.91 \%$ whereas the survival proportion including also FMT repositioning lies at $85.56 \%$. The SP group reported 1 coupler change (1 out of 9 ears) as the audiological performance was not satisfactory. For the SP group, the device survival proportion lies at $100 \%$ and the survival proportion including also the FMT repositioning lies at $83.33 \%$.

\section{Discussion}

Coupling the FMT to the long incus process after mastoidectomy with posterior tympanotomy has been the standard surgical approach for VSB implantation for years. In this study, the first long-term results up to 116 months with comparable and stable results for the LPcoupler compared to the SP-coupler (F/U up to 32 months) can be seen. Due to the design of the SP-coupler, a large and extended antrotomy must be drilled nevertheless a discontinuity or a fixation of the ossicular chain cannot be controlled with this access to the middle ear. A further crucial point is the design of the system in cases with nar- 


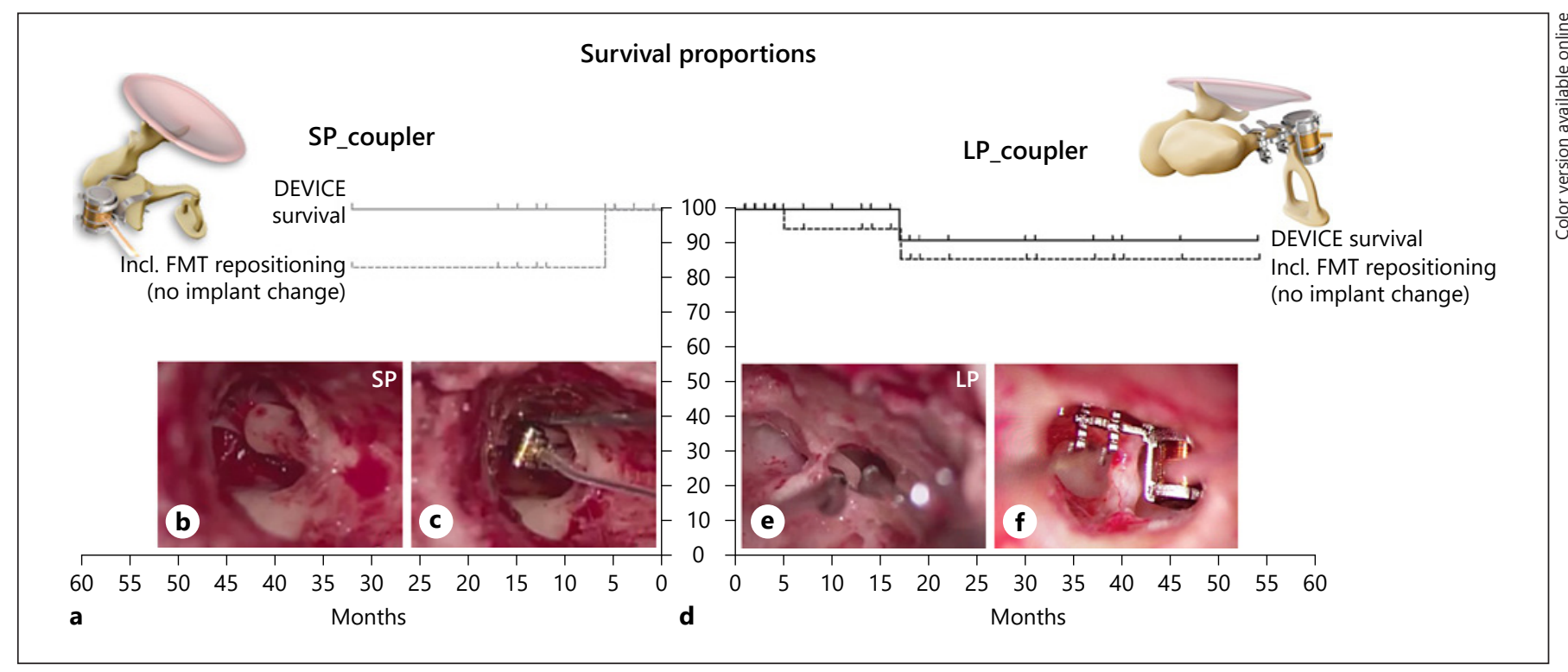

Fig. 5. Graph shows the Kaplan-Meier Survival analysis calculating the "survival" probability (left) for the SP coupler over a course of 32 months, including a coupler drawing (a; top left) as well as a surgical photo graph of the anatomical area (b; bottom left) and corresponding final coupler position (c; bottom right) (right) for the LP coupler over a course of 54 months, including a coupler drawing (d; top right) as well as a surgical photograph of the ana-

row tympanic cavities. Firm attachment of the FMT is crucial for optimal performance of the device [Fisch et al., 2001]. An adhesion around the FMT due to potential contact of the coupler with the surrounding structures may be possible even though it was not reported in these SNHL patients. In addition, the literature reports injury of the chorda tympani in $1.6 \%$ and taste disturbance in $6.5 \%$ after VSB surgery which was not observed in the cohort investigated [Fisch et al., 2001; Lenarz et al., 2001; Snik et al., 2001; Schmuziger et al., 2006; Brito et al., 2012; Zahnert et al., 2018]. No intraoperative complications in the 62 investigated cases occurred, and the post-operative complications were considerably low. In contrast to these possible risks, a longer surgical time has been reported in some papers when a LP-coupler was used which could not be observed in the here examined cohort. The mean surgery time from skin incision to close-up suture was $72.8 \mathrm{~min}$ in the LP and 71.33 min in the SP group. Potential risks have been reported when a subtotal mastoidectomy and posterior tympanotomy must be drilled for the implantation of an AMEI. Due to the dimensions of the device, the requirement of a relatively wide opening of the facial recess to allow a correct fixation of the FMT carries some increased surgical risk. These include injury of the facial tomical area (e; bottom left) and the corresponding final coupler position (f; bottom right). The survival proportion of the device survival in the LP group lies at $90.91 \%$ whereas the survival proportion including also FMT repositioning lies at $85.56 \%$. For the SP group, the device survival proportion lies at $100 \%$ and the survival proportion including also the FMT repositioning lies at $83.33 \%$. LP, long process.

nerve, facial palsy, injury of the chorda tympani, and potential taste disturbance. No case of accidental facial nerve palsy after VSB surgery has been reported in the here investigated cases. The differences in FG reported in the literature according to the position of the FMT could not be seen in our results. This was hypothesized based on the different vibration axis's of the FMT: in SP vibroplasty, it is attached closer to the incudomallear joint (MI joint) than in LP vibroplasty. The malleus, incus, and stapes are positioned in a complicated three-dimensional pattern with the 2 ends of these bones being fixed at the tympanic membrane and oval window, while the MI joint and incudostapedial joint (IS joint) are saddle and ball-and-socket synovial joints that have an unsteady and complex movement. To allow a powerful piston-like movement of the stapes towards the oval window, the FMT has to be positioned perpendicular to the stapes footplate which might not have happened in those studies [Lee et al., 2017].

The objective outcomes in terms of WRS and FG showed significant improvements after surgery independent of coupling modality applied, which was also accompanied subjective outcomes indicated by high patient satisfaction and near to normal utility scores in terms of quality-of-life measures via AQoL-8d questionnaire. 
Nonetheless, the main limitation of the study was that the AQoL-8d questionnaire was administered only after treatment, solely to recipients of the LP-coupler group and that the participation with 18 out of 40 was considerably low. Nonetheless, the direct comparison of the quality-of-life utility index with the healthy age- and sex-matched control shows the significant subjective benefit the intervention provides. It also appears as if subjects confronted with the setbacks of hearing loss, hence inadequate communication and probable isolation, clearly appreciate the surgical intervention and its positive impact on quality of life. Furthermore, it is estimated that poor fit and discomfort is the third most common cause of hearing aid nonuse and the willingness to seek other treatment options even if surgical steps are involved [Kahue et al., 2014]. Published research on patients with SNHL reported FG and WRS benefit similar between conventional hearing aids and MEIs, whereas patient-perceived outcome measures suggest that MEIs provide enhanced sound quality and eliminates disturbing occlusion effect. This knowledge, together with our experience of unproblematic and fast surgical procedures for VSB implantation, the immediate hearing gain without the necessity of rehabilitation, the low complication rate and the satisfying audiological performance may be good arguments for patient counselling.

\section{Conclusion}

Fixation of the FMT, on the SP of the incus, is a feasible, comparable, and safe procedure for VSB implantation. Comparable clinical and audiological outcomes were seen with a similar complication rate when compared to a LP vibroplasty. Both fixation methods of the floating mass transducer exhibit good clinical and audiological outcomes with high patient quality of life. The SP coupling method can be a good alternative when the long process is anatomically inaccessible, or approach is limited by anatomical reasons. No decline in the long-term F/U for clinical results was found, and results are corre- lated with high patient satisfaction and quality of life for both coupling groups. BC thresholds remained stable and below $5 \mathrm{~dB}$ difference throughout the tested frequencies. The VSB offers an effective method of rehabilitating moderate-to-severe SNHL when conventional HA are contra-indicated. FG and speech recognition improvement appears on par with optimally fitted conventional HAs but avoiding the often-reported occlusion effects. Especially, subjective quality-of-life measures suggest that the VSB provides enhanced quality of life and in the majority of the investigated cases even better than their age- and sex-matched healthy control.

\section{Statement of Ethics}

The study was approved by the ethical review committee Sigmund Freud Private University, Department of Medicine (EK089/2019). Five of the presented subjects were part of a bilateral study published by Seebacher et al. [2020] with the ethical review committee for Lower Austria (GS4-EK-4/467-2017) (all part of the LP-group). Written informed consent was not required due to the retrospective nature of the study and in accordance with lo$\mathrm{cal} /$ national guidelines.

\section{Conflict of Interest Statement}

The authors have no conflicts of interest to declare.

\section{Funding Sources}

All the authors declare that there was no external funding received during the preparation of this article.

\section{Author Contributions}

Conceived and designed the analysis: G.M.S. and A.M. Collected the data: S.H.E., M.H., P.S., and S.M. Contributed analysis tools: S.H.E., P.S., and S.M. Performed the analysis: S.H.E. Wrote the paper: S.H.E., G.M.S., and A.M.

\section{References}

Baumgartner WD, Böheim K, Hagen R, Müller $J$, Lenarz $T$, Reiss $S$, et al. The vibrant soundbridge for conductive and mixed hearing losses: European multicenter study results. Adv Otorhinolaryngol. 2010;69: $38-50$.

Brito R, Monteiro TA, Leal AF, Tsuji RK, Pinna MH, Bento RF. Surgical complications in 550 consecutive cochlear implanta- tion. Braz J Otorhinolaryngol. 2012;78(3): $80-5$.

Brkic FF, Riss D, Auinger A, Zoerner B, Arnoldner C, Baumgartner WD, et al. Long-term outcome of hearing rehabilitation with an active middle ear implant. Laryngoscope. 2019;129(2):477-81.

Bruchhage KL, Leichtle A, Schönweiler R, Todt I, Baumgartner WD, Frenzel H, et al. Systematic review to evaluate the safety, efficacy and economical outcomes of the vibrant soundbridge for the treatment of sensorineural hearing loss. Eur Arch Otorhinolaryngol. 2017;274(4):1797-806.

Colletti L, Mandalà M, Colletti V. Long-term outcome of round window vibrant soundbridge implantation in extensive ossicular chain defects. Otolaryngol Head Neck Surg. 2013; 149(1):134-41. 
Cremers CW, O'Connor AF, Helms J, Roberson $\mathrm{J}$, Claros P, Frenzel H, et al. International consensus on Vibrant Soundbridge(R) implantation in children and adolescents. Int J Pediatr Otorhinolaryngol. 2010;74(11):1267-9.

Ernst A, Todt I, Wagner J. Safety and effectiveness of the vibrant soundbridge in treating conductive and mixed hearing loss: a systematic review. Laryngoscope. 2016;126(6):1451-7.

Fisch U, Cremers CW, Lenarz T, Weber B, Babighian G, Uziel AS, et al. Clinical experience with the Vibrant Soundbridge implant device. Otol Neurotol. 2001;22(6):962-72.

Fraysse B, Lavieille JP, Schmerber S, Enée V, Truy E, Vincent C, et al. A multicenter study of the Vibrant Soundbridge middle ear implant: early clinical results and experience. Otol Neurotol. 2001;22(6):952-61.

Frenzel H, Sprinzl G, Streitberger C, Stark T, Wollenberg B, Wolf-Magele A, et al. The vibrant soundbridge in children and adolescents: preliminary European multicenter results. Otol Neurotol. 2015;36(7):1216-22.

Geiger U, Radeloff A, Hagen R, Cebulla M. Intraoperative estimation of the coupling efficiency and clinical outcomes of the vibrant soundbridge active middle ear implant using auditory brainstem response measurements. Am J Audiol. 2019;28(3):553-9.

Hawthorne G, Osborne R. Population norms and meaningful differences for the assessment of quality of life (AQoL) measure. Aust N Z J Public Health. 2005;29(2):136-42.

Kahue CN, Carlson ML, Daugherty JA, Haynes DS, Glasscock ME 3rd. Middle ear implants for rehabilitation of sensorineural hearing loss: a systematic review of FDA approved devices. Otol Neurotol. 2014;35(7):1228-37.
Kliess MK, Ernst A, Wagner J, Mittmann P. The development of active middle ear implants: a historical perspective and clinical outcomes. Laryngoscope Investig Otolaryngol. 2018; 3(5):394-404

Labassi S, Beliaeff M, Pean V, Van de Heyning P. The vibrant soundbridge(R) middle ear implant: a historical overview. Cochlear Implants Int. 2017;18(6):314-23.

Lee JM, Lee YH, Jung J, Kim SH, Moon IS, Choi JY. Audiologic gain of incus short process vibroplasty with conventional incus long process vibroplasty: a retrospective analysis of 36 patients. Otol Neurotol. 2017;38(8):1063-70.

Lenarz T, Weber BP, Issing PR, Gnadeberg D, Ambjørnsen K, Mack KF, et al. [Vibrant sound bridge system. a new kind hearing prosthesis for patients with sensorineural hearing loss. 2. Audiological results]. Laryngorhinootologie. 2001;80(7):370-80. German.

Löhler J, Akcicek B, Pilnik M, Saager-Post K, Dazert S, Biedron S, et al. Evaluation des Freiburger Einsilbertests im Störschall. HNO. 2013, 61(7):586-91.

Mlynski R, Dalhoff E, Heyd A, Wildenstein D, Rak K, Radeloff A, et al. Standardized active middle-ear implant coupling to the short incus process. Otol Neurotol. 2015;36(8):1390-

Pok SM, Schlögel M, Böheim K. Clinical experience with the active middle ear implant vibrant soundbridge in sensorineural hearing loss. Adv Otorhinolaryngol. 2010;69:51-8.

Schmuziger N, Schimmann F, àWengen D, Patscheke J, Probst R. Long-term assessment after implantation of the vibrant soundbridge device. Otol Neurotol. 2006;27(2):183-8.
Schraven SP, Dalhoff E, Wildenstein D, Hagen R, Gummer AW, Mlynski R. Alternative fixation of an active middle ear implant at the short incus process. Audiol Neurootol. 2014;19(1): $1-11$.

Seebacher J, Weichbold V, Schörg P, Koci V, Magele A, Zorowka P, et al. Subjective hearing impression and quality of life in patients with bilateral active middle ear implants. Otol Neurotol. 2020;41(6):e641-7.

Snik AF, Mylanus EA, Cremers CW, Dillier N, Fisch U, Gnadeberg D, et al. Multicenter audiometric results with the vibrant soundbridge, a semi-implantable hearing device for sensorineural hearing impairment. Otolaryngol Clin North Am. 2001;34(2):373-88.

Sprinzl GM, Riechelmann H. Current trends in treating hearing loss in elderly people: a review of the technology and treatment options - a mini-review. Gerontology. 2010; 56(3):351-8

Sprinzl GM, Schoerg P, Muck S, Jesenko M, Speiser S, Ploder M, et al. Long-term stability and safety of the soundbridge coupled to the round window. The Laryngoscope. 2021;131(5):E1434-42.

Sterkers O, Boucarra D, Labassi S, Bebear JP, Dubreuil C, Frachet B, et al. A middle ear implant, the symphonix vibrant soundbridge: retrospective study of the first 125 patients implanted in France. Otol Neurotol. 2003; 24(3):427-36.

Wolf-Magele A, Schnabl J, Woellner T, Koci V, Riechelmann H, Sprinzl GM. Active middle ear implantation in elderly people: a retrospective study. Otol Neurotol. 2011;32(5): 805-11.

Zahnert T, Mlynski R, Löwenheim H, Beutner D, Hagen R, Ernst A, et al. Long-term outcomes of vibroplasty coupler implantations to treat mixed/conductive hearing loss. Audiol Neurootol. 2018;23(6):316-25. 